Revista de

Contabilidade e

Organizações

www.rco.usp.br
DOI: http://dx.doi.org/10.11606/issn.1982-6486.rco.2018.139161
Journal of

Accounting and

Organizations

\title{
Cultura organizacional e desempenho nas empresas estrangeiras listadas na NYSE
}

\section{Organizational culture and performance of foreign firms listed on the NYSE}

Paulo Henrique Nobre Parente ${ }^{\mathrm{a}}$; Marcia Martins Mendes De Lucab; Gerlando Augusto Sampaio Franco de Limac; Alessandra Carvalho de Vasconcelos ${ }^{\mathrm{b}}$

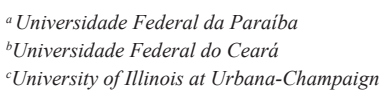

Palavras-chave

Cultura organizacional.

Tipologias culturais.

Desempenho.

\section{Resumo}

Fundamentado nos preceitos da teoria da visão baseada em recursos, o estudo investiga a cultura organizacional como recurso estratégico sustentável para o desempenho das empresas estrangeiras listadas na New York Stock Exchange. Analisou-se a cultura organizacional de 141 empresas pela análise textual dos relatórios 20-F apresentados por elas à US Securities and Exchange Commission, entre 2009 e 2014, classificando os radicais de palavras em quatro tipologias culturais. Os resultados mostram a predominância de uma cultura organizacional mais competitiva, enquanto a cultura organizacional criativa tem menor representatividade. Os resultados revelam ainda que a cultura colaborativa e de controle influenciam, respectivamente, de forma positiva e negativa o desempenho financeiro. Estes efeitos são distintos entre a origem das empresas e entre o tipo do sistema legal dos países de origem das empresas. Considerando que a cultura organizacional pode ser considerada um ativo estratégico capaz de afetar o desempenho financeiro da empresa, sugere-se que gestores, investidores e acadêmicos, fiquem atentos à cultura organizacional como um componente da estratégia dos negócios.

\begin{abstract}
Supported by the Resource-Based View theoretical approach, we evaluated the organizational culture as a sustainable and strategic resource for foreign firms listed on the New York Stock Exchange. We performed a text analysis of SEC 20-F forms from 141 firms issued from 2009 up to 2014, classifying key words according to four types of organizational culture (collaborate, create, competition, control). The evidences support that the 'competitive' and 'creative' organizational cultures were the most and less representative types, respectively. 'Collaborative' and 'control' cultures presented a positive and negative effect, respectively, on corporate financial performance. Finally, the effects of the organizational culture type were influenced by the country of origin and by legal system operating in the firm's home country. Our results support that organizational culture is an important strategic component for financial performance which deserves more attention from managers, investors and academics.
\end{abstract}

\section{Implicações práticas}

O tipo de cultura organizacional desenvolvido na organização tem relação com o desempenho financeiro. As empresas estrangeiras de capital aberto presentes da Nyse, especificamente as de origem europeia são beneficiadas pela presença de uma cultura colaborativa. Executivos e analistas podem passar a considerar o desenvolvimento do capital cultural-corporativo como fator de geração de valor.

Copyright (C) 2018 FEA-RP/USP. Todos os direitos reservados

\footnotetext{
Autor Correspondente: Tel. (85) 33667300

E-mail:paulonobreparente@yahoo.com.br (P. H. N. Parente); marciammdeluca@gmail.com (M. M. M. De Luca); gerlandolima@gmail.com (G. A. S. F. Lima); alevasconcelos.ufc@gmail.com (A. C. Vasconcelos);

Universidade Federal do Ceará. Av. da Universidade, 2853 - Benfica, Fortaleza - CE, 60020-181, Brasil
} 


\section{INTRODUÇ̃̃O}

A literatura explora diferentes perspectivas de cultura organizacional, sendo que parte dela investiga a relação entre cultura organizacional e desempenho como uma relação adaptativa e integrativa da empresa com o meio. Neste estudo, coaduna-se com o conceito cultura organizacional (ou corporativa) de Schein (1984, p. 17), que a define como "um conjunto de premissas que um grupo aprendeu a aceitar, como resultado da solução de problemas de adaptação ao ambiente e de integração interna".

Embora haja interesse pelo estudo dos efeitos da cultura no desempenho corporativo, há ainda pouca clareza sobre essa conexão (O’Reilly III, Caldwell, Chatman \& Doerr, 2014). Gregory, Harris, Armenakis e Shook (2009) destacam que poucos estudos fornecem informações detalhadas sobre esse relacionamento. Entretanto, pesquisas mais recentes começam a explorar fortemente este vínculo (Acar \& Acar, 2014; Fekete \& Böcskei, 2011; Han, 2012; Ogbonna \& Harris, 2000; Tseng, 2010; Yesil \& Kaya, 2013).

Pesquisadores e gestores exploram diferentes perspectivas para a relação entre a cultura organizacional e o desempenho empresarial (Duke II \& Edet, 2012), destacando-se que culturas organizacionais fortes direcionam a um melhor desempenho. Existe também uma associação reversa, em que o alto desempenho leva à criação de uma forte cultura organizacional; e ainda, que uma cultura adaptativa é considerada essencial para um bom desempenho, pois ajuda a organização obter respostas às mudanças no ambiente em que atua.

A literatura reconhece também que a cultura organizacional pode ser considerada um ativo estratégico capaz de gerar vantagem competitiva sustentável (Flamholtz \& Ranndle, 2012) e, como um recurso estratégico, pode ser a essência de um modelo de negócio bem-sucedido (Barney, 1986). Pode-se citar como exemplo do recurso estratégico intangível as culturas corporativas de empresas como Starbucks, Southwest Airlines, Wal-Mart ou Google (Flamholtz \& Ranndle, 2012).

Segundo a abordagem da Visão Baseada em Recursos (RBV na sigla em inglês), a cultura somente proporcionará vantagem competitiva sustentável quando for valiosa, rara e imperfeitamente imitável (Barney, 1986). Culturas organizacionais com esses atributos são aquelas em que as empresas apresentam produtos e serviços que são preferidos pelos atuais e potenciais clientes em função da marca desses produtos; capacidade de atrair, motivar e reter o capital humano; desenvolvimento continuado de produtos e serviços inovadores; e modelos de negócios competitivos (Flamholtz \& Ranndle, 2012). Barney (1986) afirma que a presença desses atributos valiosos, raros e inimitáveis - devem ter um efeito positivo nos lucros.

Empiricamente, estudos já apontam o efeito da cultura organizacional no desempenho corporativo (Deal \& Kennedy, 1982; O’Reilly III et al., 2014), sugerindo que esta é capaz de ter impactos positivos no lucro, na rentabilidade e no preço das ações. Outras evidências mostram que a cultura organizacional - medida por tipologias culturais - afeta o desempenho da empresa de formas distintas (Acar \& Acar, 2014; Fekete \& Böcskei, 2011; Han, 2012; Ogbonna \& Harris, 2000; Tseng, 2010; Yesil \& Kaya, 2013). Estes últimos estudos adotam a classificação de Cameron, Quinn, Degraff e Thakor (2006) na denominada Competing Values Framework (CVF), a qual tipifica a cultura organizacional em colaborativa, criativa, competitiva e de controle.

Os estudos ainda apontam uma relação entre cultura organizacional e eficácia da organização, mas os resultados empíricos permanecem indefinidos (O'Reilly III et al., 2014). A eficácia organizacional é representada pela satisfação e comprometimento dos empregados, inovação de produtos e serviços, participação de mercado, lucro, qualidade do produto e produtividade e eficiência (Cameron \& Quinn, 1999, Cameron et al., 2006, Fekete \& Böcskei, 2011, Han, 2012). Diferentes tipologias culturais gerariam distintos resultados em termos de eficácia organizacional, que, por sua vez, afetariam distintivamente o desempenho financeiro, avaliado por medidas de rentabilidade e de criação de valor, por exemplo.

Assim, o objetivo do artigo é analisar o efeito da cultura organizacional, como recurso estratégico sustentável, no desempenho financeiro das empresas estrangeiras listadas na Nyse. Considerando que fatores institucionais como "as restrições humanamente concebidas que estruturam a interação política, econômica e social" (North, 1991, p. 97) podem divergir entre os ambientes. Este estudo, adicionalmente, investiga a relação entre cultura e desempenho a partir dos diferentes contextos regionais (continente de origem) e jurídicos (sistema legal) dos países sede das empresas.

Foram selecionadas 141 empresas estrangeiras listadas na Nyse, distribuídas em 34 países de origem. Os relatórios 20-F, apresentados por estas empresas à US Securities and Exchange Commission (SEC) entre 2009 a 2014, foram utilizados como fonte de análise de conteúdo para captar a cultura organizacional da empresa. Foram empregados os procedimentos de Fiordelisi e Ricci (2014) para identificar o discurso da gestão nas narrativas presentes nesses relatórios. 
Aplicou-se em seguida regressão múltipla com dados em painel, bem como análise de regressão por mínimos quadrados generalizados e regressão com variáveis instrumentais para minimizar problemas de endogeneidade dos regressores. Em relação aos estudos anteriores que adotam o modelo Competing Values Framework a amostra inova comparando empresas de capital aberto de diversos países de origem, que negociam ações na Nyse, permitindo comparar suas narrativas em um mesmo relatório em um mesmo idioma.

Com isto, é possível comparar como a cultura organizacional se associa com os continentes dos países de origem e os sistemas legais desses países. Os resultados mostram que a cultura colaborativa e de controle afetam positiva e negativamente o desempenho da firma, respectivamente, conforme preceitua a abordagem da Visão Baseada em Recursos (RBV). Os resultados da análise de sensibilidade - por continente de origem e por sistema legal - sugerem que as tipologias de cultura organizacional afetam de forma distinta o desempenho das organizações. A cultura organizacional das empresas europeias tem efeito no desempenho financeiro, especificamente uma cultura colaborativa afeta positivamente o desempenho, enquanto que as culturas criativa e competitiva afetam negativamente o desempenho.

Quando analisado por sistema legal, as regras e normas positivistas e rígidas de países civil law, estão associadas com o efeito de culturas organizacionais colaborativa e criativa no desempenho de empresas que têm origem em países com este sistema legal. Por outro lado, nas empresas sediadas em países com sistemas common law, cujas regras e normas são flexíveis e dinâmicas, a cultura organizacional criativa reduz o desempenho das empresas. Quando o país de origem opera com um sistema legal misto, são as culturas criativa e de controle que afetam o desempenho financeiro das empresas.

Destaca-se que a literatura sobre o tema tem concentrado análises em mercados e setores específicos, bem como utilizado métricas com abordagem interpretativista. Este estudo diferencia-se, portanto, ao expor uma visão sistêmica da cultura organizacional e do desempenho financeiro empresarial em diferentes contextos e a partir de abordagem empírica, normalmente não aplicada em estudos sobre cultura (Fiordelisi \& Ricci, 2014). Espera-se, portanto, contribuir com uma análise da relação cultura-desempenho de empresas que, embora apresentem fatores institucionais distintos, participam de um mercado altamente competitivo como a Nyse. O estudo se justifica também na medida em que contribui para a complexa tarefa de mensurar a cultura organizacional, aqui identificada como um recurso estratégico que gera vantagem competitiva, conforme preceitos da teoria da visão baseada em recursos.

\section{REVISÃO DE LITERATURA E HIPÓTESES}

Na visão de Schein (1984), a cultura organizacional abrange um conjunto de premissas consideradas válidas para um grupo, que podem ser ensinadas a novos integrantes desse grupo, que passam a adotá-las como a forma correta de perceber e sentir-se em relação às questões de adaptação e de integração interna. Dessa forma, considerando que as questões de adaptação e integração ao ambiente são fundamentais para uma boa performance empresarial, diversos estudos têm investigado a relação entre a cultura organizacional e o desempenho empresarial.

A cultura organizacional compreende um conjunto de elementos - representada por valores, abordagens e suposições - que caracterizam as empresas, de modo que cada perfil cultural pode influenciar, distintivamente, o sucesso da firma, levando em conta as necessidades do ambiente externo e a sua orientação estratégica (Cameron \& Quinn, 1999, Cameron et al., 2006). Cameron et al. (2006) classificam a cultura organizacional em dimensões e tipologias, sob a denominação de Competing Values Framework (CVF) (Figura 1).

As tipologias culturais originam-se a partir da existência de conflitos entre os valores culturais corporativos (Cameron et al., 2006). Dessa forma, a combinação das dimensões culturais, a partir do enfoque (interno e externo) e da estrutura (orgânica ou mecânica), resulta em quatro perfis, que caracterizam as diferentes culturas corporativas, denominadas Clã (ou colaborativa), Adhocracia (ou criativa), Hierárquica (ou controladora) e Mercado (ou competitiva).

Diferentes tipologias culturais implicam em diferentes resultados em termos de eficácia organizacional, afetando distintamente o desempenho (Acar \& Acar, 2014, Ahmed \& Shafiq, 2014, Fekete \& Böcskei, 2011, Tseng, 2010, Yesil \& Kaya, 2013). Alguns autores apresentam argumentos que fortalecem a posição da cultura organizacional como um ativo estratégico que pode afetar o desempenho, gerando vantagem competitiva sustentável (Barney, 1986; Flamholtz \& Randle, 2012). Conforme já mencionado, diversos argumentos são narrados para explicar a relação entre a cultura e o desempenho corporativo (Duke II \& Edet, 2012). 
Figura 1. Competing Values Framework

\section{Flexibilidade e Discrição}

\begin{tabular}{|c|c|}
\hline $\begin{array}{c}\text { Cultura Clã } \\
\text { Orientação Colaborativa } \\
\text { Meios Coesão, participação, } \\
\text { comunicação, capacitação } \\
\text { Fins Moral, desenvolvimento de pessoas, } \\
\text { comprometimento }\end{array}$ & $\begin{array}{c}\text { Cultura Adhocracia } \\
\text { Orientação Criativa } \\
\text { Meios Adaptabilidade, criatividade, } \\
\text { agilidade } \\
\text { Fins Inovação e tecnologia de ponta }\end{array}$ \\
\hline $\begin{array}{c}\text { Cultura Hierárquica } \\
\text { Orientação Controle } \\
\text { Meios Processos capazes, consistência, } \\
\text { controle de processos e medição } \\
\text { Fins Eficiência, pontualidade, bom } \\
\text { funcionamento }\end{array}$ & $\begin{array}{c}\text { Cultura Mercado } \\
\text { Orientação Competição } \\
\text { Meios Foco no cliente, produtividade, } \\
\text { aumentar a competitividade } \\
\text { Fins Participação de mercado, } \\
\text { rentabilidade, alcance de metas }\end{array}$ \\
\hline
\end{tabular}

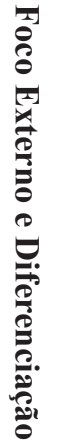

Estabilidade e Controle

Fonte: Adaptada de Cameron et al. (2006).

A primeira abordagem é a de que culturas organizacionais fortes sempre levam a melhores níveis de desempenho. Já a segunda baseia-se na concepção de contingência, uma vez que em certas condições uma tipologia cultural é mais apropriada, e, então, contribuiria para a eficiência empresarial. A terceira propõe que especificamente a cultura organizacional adaptativa levaria ao bom desempenho, pois ajudaria a organização a responder às mudanças no ambiente. Uma quarta abordagem sugere uma associação reversa entre a cultura organizacional e o desempenho, em que é o elevado desempenho que desenvolve uma forte cultura organizacional. Por fim, a visão mais recente propõe que a cultura organizacional é um recurso estratégico sustentável (Flamholtz \& Randle, 2012) e fonte de vantagem competitiva, a essência de um modelo de negócio (Barney, 1986).

Nesta última visão, pela abordagem da Visão Baseada em Recursos (RBV), a cultura organizacional exerceria um efeito positivo sobre os lucros, difícil de ser imitado, escasso (Barney, 1986) e sustentável por, pelo menos, um período superior a dois anos (Flamholtz \& Randle, 2012). A difícil imitação também viria do intricado efeito da cultura em outros elementos como satisfação e comprometimento dos empregados, inovação de produtos e serviços, participação de mercado, lucro, qualidade do produto e produtividade, afeta o desempenho da empresa (Cameron \& Quinn, 1999, Cameron et al., 2006, Fekete \& Böcskei, 2011, Han, 2012). Desse modo, para cada tipologia cultural há resultados específicos, em razão da eficácia organizacional.

A literatura cultura-desempenho tem encontrado limitações e resultados inconclusivos. Hartnell, Ou e Kinicki (2011) analisaram 31 estudos que investigaram a relação cultura-desempenho e concluíram que há poucos estudos sobre a relação entre a cultura e o desempenho financeiro; as amostras são pequenas; e os resultados são substancialmente divergentes. Tais achados corroboram o levantamento apresentado no Quadro 1. Observa-se ainda que os instrumentos utilizados para a identificação da cultura organizacional nas pesquisas são essencialmente baseados em dados primários (Ahmed \& Shafiq, 2014; Lee \& Yu, 2004; Santos, 1998), segundo diferentes bases teóricas (Fiordelisi \& Ricci, 2014). Tal diversidade mostra a complexidade das pesquisas em cultura organizacional.

O presente estudo adota o modelo Competing Value Framework como modelo de análise, assim como outros estudos que são apresentados no Quadro 1 a seguir. Desse modo, propomos que cada tipologia cultural - colaborativa, criativa, competitiva e de controle - possui elementos específicos que afetam, de forma distinta, a eficácia organizacional, e que, por sua vez, influencia o desempenho, partindo da premissa que a cultura organizacional é considerada um recurso estratégico sustentável, conforme a abordagem da Visão Baseada em Recursos.

Empresas com cultura colaborativa reconhecem a participação dos empregados e incentivam o trabalho em equipe, além da predominância de características como a confiança e a solidariedade (Acar \& Acar, 2014). Entre as 4 tipologias, a colaborativa é mais próxima do conceito geral de cultura, pois é pelos indivíduos que os valores, as crenças e as normas são disseminados na empresa (Schein, 1984). Praticamente todos estudos anteriores no Quadro 1 mostram que a cultura colaborativa influencia positivamente o desempenho, indiferentemente do setor, país ou sistema jurídico ao qual a empresa esteja inserida, mostrando que a tipologia colaborativa é a mais representativa em relação às demais tipologias (Han, 2012). Assim:

$\mathbf{H}_{1 \mathbf{a}}$ : A cultura organizacional colaborativa afeta positivamente o desempenho financeiro da empresa estrangeira listada na Nyse. 


\begin{tabular}{|c|c|c|c|c|}
\hline Autor(es) & Amostra e [desempenho] & Modelo & $\begin{array}{l}\text { Associação identificada } \\
\text { (sinal entre parênteses) }\end{array}$ & $\begin{array}{c}\text { Competing } \\
\text { Value } \\
\text { Framework }\end{array}$ \\
\hline $\begin{array}{l}\text { Ogbonna e } \\
\text { Harris }(2000)\end{array}$ & $\begin{array}{l}322 \text { empresas de capital } \\
\text { aberto do Reino Unido, } \\
\text { [lucratividade] }\end{array}$ & $\begin{array}{l}\text { Regressão moderada pela } \\
\text { liderança organizacional }\end{array}$ & $\begin{array}{c}(+) \text { competitiva; }(+) \\
\text { inovativa } \\
\text { (demais não significantes) }\end{array}$ & Sim \\
\hline Tseng (2010) & $\begin{array}{l}131 \text { empresas de capital } \\
\text { aberto da Tailândia } \\
\text { [financeiro, mercado, } \\
\text { processo] }\end{array}$ & $\begin{array}{l}\text { Correlação, comparando } \\
\text { com a conversão de } \\
\text { conhecimento }\end{array}$ & $\begin{array}{c}(+) \text { criativa } \\
\text { (demais não significantes) }\end{array}$ & Sim \\
\hline Han (2012) & $\begin{array}{c}99 \text { hotéis da Coreia do } \\
\text { Sul [retorno sobre o } \\
\text { investimento] }\end{array}$ & $\begin{array}{l}\text { Regressão mediada pela } \\
\text { orientação estratégica }\end{array}$ & $\begin{array}{c}(+) \text { colaborativa; }(+) \\
\text { criativa; }(-) \text { controle; } \\
\text { competitiva insignificante }\end{array}$ & Sim \\
\hline $\begin{array}{l}\text { Yesil e Kaya } \\
\quad(2013)\end{array}$ & $\begin{array}{l}54 \text { empresas da Turquia } \\
\text { registradas na Câmara de } \\
\text { Comércio de Gaziantep } \\
\text { [retorno sobre ativos] }\end{array}$ & $\begin{array}{l}\text { Regressão controlada pelo } \\
\text { setor, tamanho e idade }\end{array}$ & $\begin{array}{c}\text { Nenhuma tipologia cultural } \\
\text { foi significativa }\end{array}$ & Sim \\
\hline $\begin{array}{l}\text { Acar e Acar } \\
\text { (2014) }\end{array}$ & $\begin{array}{c}99 \text { hospitais públicos } \\
\text { e privados da Turquia, } \\
\text { [desempenho financeiro e } \\
\text { de serviços] }\end{array}$ & $\begin{array}{l}\text { Regressão mediada pelo } \\
\text { tamanho e idade }\end{array}$ & $\begin{array}{c}(+) \text { colaborativa; }(+) \\
\text { criativa; }(+) \text { controle; }(+) \\
\text { competitiva }\end{array}$ & Sim \\
\hline Santos (1998) & $\begin{array}{c}13 \text { empresas têxteis de } \\
\text { capital aberto do Brasil } \\
\text { [liquidez, endividamento, } \\
\text { retorno sobre o patrimônio } \\
\text { líquido] }\end{array}$ & $\begin{array}{l}\text { Análise de clusters (culturas } \\
\text { fortes e fracas), comparação } \\
\text { de médias e correlação }\end{array}$ & $\begin{array}{c}\text { Cultura está associada } \\
\text { com desempenho. } \\
\text { Empresas com forte } \\
\text { cultura evidenciam melhor } \\
\text { desempenho }\end{array}$ & Não \\
\hline $\begin{array}{l}\text { Lee e Yu } \\
(2004)\end{array}$ & $\begin{array}{c}10 \text { empresas de Singapura } \\
\text { do setor de manufatura, } \\
\text { hospitais e seguro } \\
\text { [diversas métricas] }\end{array}$ & $\begin{array}{c}\text { Correlação entre a cultura e } \\
\text { desempenho }\end{array}$ & $\begin{array}{c}\text { Cultura impacta as } \\
\text { diferentes medidas de } \\
\text { desempenho. Força cultural } \\
\text { majora o desempenho }\end{array}$ & Não \\
\hline $\begin{array}{l}\text { Duke II e Edet } \\
\quad(2012)\end{array}$ & $\begin{array}{l}99 \text { ONGs da Nigéria } \\
\text { [clientes atendidos, custo } \\
\text { por serviço prestado] }\end{array}$ & $\begin{array}{l}\text { Regressão sem variáveis } \\
\text { mediadoras. }\end{array}$ & $\begin{array}{c}\text { A cultura afeta } \\
\text { positivamente todas as } \\
\text { medidas de desempenho }\end{array}$ & Não \\
\hline $\begin{array}{l}\text { Kotrba, } \\
\text { Gillespie, } \\
\text { Schmidt, } \\
\text { Smerek, } \\
\text { Ritchie e } \\
\text { Denison } \\
(2012)\end{array}$ & $\begin{array}{c}98 \text { empresas de capital } \\
\text { aberto ao redor do mundo } \\
\text { [market-to-book, retorno } \\
\text { sobre ativos, crescimento } \\
\text { das vendas] }\end{array}$ & $\begin{array}{l}\text { Regressão interativa da } \\
\text { cultura e desempenho }\end{array}$ & $\begin{array}{l}\text { Culturas consistentes } \\
(+) \text {, adaptáveis }(+) \text { e } \\
\text { envolvimento }(-)\end{array}$ & Não \\
\hline $\begin{array}{c}\text { Ahmed e } \\
\text { Shafiq (2014) }\end{array}$ & $\begin{array}{c}15 \text { franquias de } \\
\text { telecomunicações de } \\
\text { Baaualpur [desempenho } \\
\text { financeiro, consumidor e } \\
\text { produção] } \\
\end{array}$ & $\begin{array}{l}\text { Regressão sem variáveis } \\
\text { mediadoras }\end{array}$ & $\begin{array}{l}\text { A cultura afeta todas } \\
\text { as perspectivas de } \\
\text { desempenho }\end{array}$ & Não \\
\hline $\begin{array}{l}\text { O'Reilly III et } \\
\text { al. (2014) }\end{array}$ & $\begin{array}{l}32 \text { empresas de capital } \\
\text { aberto de tecnologia } \\
\text { dos Estados Unidos e } \\
\text { da Irlanda [crescimento } \\
\text { da receita, Q de Tobin, } \\
\text { reputação] }\end{array}$ & $\begin{array}{c}\text { Regressão entre } \\
\text { personalidade do CEO, } \\
\text { cultura e desempenho, } \\
\text { mediada pelos subsetores e } \\
\text { tamanho }\end{array}$ & $\begin{array}{c}\text { Cultura }(+) \text { adaptabilidade, } \\
(+) \text { integridade },(+) \\
\text { detalhista, }(+) \text { orientada } \\
\text { aos resultados. Demais } \\
\text { (colaboração, consumidor) } \\
\text { não significantes }\end{array}$ & Não \\
\hline $\begin{array}{l}\text { Santos et al. } \\
\quad(2014)\end{array}$ & $\begin{array}{l}368 \text { empresas de médio } \\
\text { e grande porte do Brasil } \\
\text { que atuam no país e } \\
\text { no exterior [financeiro, } \\
\text { mercado, processos e } \\
\text { capacidades, aprendizado] }\end{array}$ & $\begin{array}{l}\text { Equações estruturais } \\
\text { entre cultura, estrutura } \\
\text { organizacional, gestão de } \\
\text { pessoas e desempenho }\end{array}$ & $\begin{array}{l}\text { A cultura é o componente } \\
\text { mais explicativo do } \\
\text { desempenho }\end{array}$ & Não \\
\hline
\end{tabular}

Quadro 1. Cultura e desempenho

Fonte: Dados da pesquisa. 
Da mesma forma, a cultura criativa afeta positivamente o desempenho, porém por motivos diversos. Organizações com cultura organizacional tipicamente criativa são voltadas para o ambiente externo, e convertem melhor o conhecimento em desempenho (Tseng, 2010). O foco em inovação possibilita aumentar a capacidade da empresa no rápido e eficiente desenvolvimento de novos produtos (Naor, Jones, Bernardes, Goldstein \& Schroeder, 2014). E, considerando a adaptabilidade ao meio externo, a cultura criativa nestas empresas tem o potencial de afetar positivamente seus resultados (Kim, Lee \& Yu, 2004).

A cultura organizacional da tipologia criativa tem mostrado relação positiva com o desempenho, exceção é o estudo de Yesil e Kaya (2013). Essas evidências revelam que, independentemente do nível de competitividade do mercado, as empresas com forte cultura criativa apresentam melhores níveis de desempenho. Propõe-se que: na Nyse.

$\mathbf{H}_{\mathbf{1 b}}$ : A cultura organizacional criativa afeta positivamente o desempenho da empresa estrangeira listada

Com valores orientados para a realização de metas, a cultura competitiva consiste na definição de metas claras e recompensas associadas ao atingimento de tais metas para motivar os indivíduos e satisfazer as expectativas dos stakeholders de forma agressiva (Hartnell et al., 2011). Tal cultura orientada para o mercado tem sido considerada um elemento-chave de um desempenho superior, embora alguns estudos não tenham encontrado evidências empíricas dessa associação (Han, 2012; Yesil \& Kaya, 2013). Fekete e Böcskei (2011) enfatizam que esse tipo de cultura se concentra na busca por eficácia, eficiência e competitividade, o que, por sua vez, ajuda a melhorar os resultados. Nas empresas que participam de mercados desenvolvidos, como a Nyse, espera-se elevado nível de competitividade, o que poderia disparar a presença de tal tipologia. Propõe-se que:

$\mathbf{H}_{1 \mathbf{c}}$ : A cultura organizacional competitiva afeta positivamente o desempenho financeiro da empresa estrangeira listada na Nyse.

Por fim, em uma cultura organizacional típica de controle, predomina a crença de que os colaboradores atendem às expectativas quando seus papéis são claramente definidos (Hartnell et al., 2011). Tal cultura é centrada, principalmente, na reduzida autonomia dos indivíduos, na ausência de propósitos e em objetivos pouco delineados (Cameron \& Quinn, 1999).

Os efeitos da tipologia de controle apresentam diversidade de evidências empíricas, indicando que as características de eficácia carregadas pelas empresas podem afetar o desempenho positiva ou negativamente, mostrando-se distinto a partir de características como o setor. Por um lado, a cultura de controle parece melhorar os níveis de desempenho de hospitais (Acar \& Acar, 2014). No setor hoteleiro, porém, o resultado é diferente (Han, 2012), sugerindo que em setores mais dinâmicos a cultura de controle é menos presente, mas quando é a dominante na organização acaba reduzindo os níveis de desempenho. Nesse tipo de cultura, entende-se ainda que o controle, a estabilidade e a previsibilidade promovem eficiência e, consequentemente, melhora o desempenho (Hartnell et al., 2011). Todavia, a cultura organizacional de controle tende a reduzir o desempenho, principalmente, em razão da rigidez do processo de tomada de decisões (Han, 2012; Ogbonna \& Harris, 2000).

Por fim, os estudos anteriores mostram que a cultura de controle não é melhor em comparação às demais tipologias (Tseng, 2010), pois as empresas com tal tipologia são menos eficientes por serem excessivamente formalizadas (Ogbonna \& Harris, 2000) e com maior foco voltado para os aspectos internos à organização (Ogbonna \& Harris, 2000; Tseng 2010). Portanto:

$\mathbf{H}_{1 \mathbf{d}}$ : A cultura organizacional de controle afeta negativamente o desempenho financeiro da empresa estrangeira listada na Nyse.

\section{PROCEDIMENTOS METODOLÓGICOS}

A composição da amostra partiu de 520 empresas estrangeiras listadas na Nyse (com sede fora dos EUA) em 31/07/2015. Excluíram-se para a amostra final 201 empresas que não haviam publicado seus respectivos relatórios anuais modelo 20-F; outras 45 financeiras para isolar os efeitos de suas características operacionais em relação ao restante da amostra; outras 31 empresas cujo exercício social difere do ano civil; e por fim, 102 empresas que deixaram de publicar o relatório 20-F em pelo menos um dos exercícios analisados. A amostra final foi composta então, por 141 empresas (a lista das empresas pode ser consultada no material suplementar).

Embora os relatórios 20-F tenham caráter obrigatório de divulgação pelas empresas estrangeiras, alguns destes não foram encontrados na base de dados Edgar. A ausência desses relatórios pode gerar uma análise limitada dos dados. A Tabela 1 apresenta a distribuição da amostra por setor ou ramo de atividade econômica, por continente de origem e por sistema legal/jurídico do país sede da empresa. 
Foram analisados os relatórios 20-F, de 2009 a 2014, disponíveis no website da U. S. Securities and Exchange Commission (SEC) (Edgar database) totalizando 846 relatórios analisados. O relatório 20-F é obrigatório para empresas estrangeiras detentoras de ações negociadas na bolsa dos EUA. O objetivo do regulador é tornar as informações divulgadas por essas empresas comparáveis com as empresas norte-americanas.

O relatório 20-F cobre atividades operacionais-chave, riscos de mercado, controles internos, código de ética e conduta, governança corporativa, demonstrações financeiras e auditoria. Deve ser divulgado em inglês, em até 180 dias após o término do exercício fiscal. A exigência para elaboração e divulgação do relatório 20-F está presente nas seções 12(b) e (g), 13 e 15(d) do Securities and Exchange Act, de 1934. A SEC disponibiliza um modelo, contendo instruções gerais para registro do relatório 20-F bem como para a sua elaboração. Inclui ainda as normas aplicáveis às empresas estrangeiras, período para arquivamento do relatório e declarações de registro, regras e regulamentos gerais.

Cada um dos 846 relatórios foi submetido a uma análise de texto, para se estimar cada tipologia cultural, segundo o Competing Value Framework, para a construção da variável cultura organizacional A análise de texto permite examinar, de forma sistemática e objetiva, as características específicas dos textos (Stone, Dunphy, Smith \& Ogilvie, 1966). A técnica se baseia na suposição de que as palavras e as expressões usadas por membros de uma empresa, identificadas através de um vocabulário, representam o resultado da cultura que a empresa desenvolve ao longo do tempo (Levinson, 2003). Para Fiordelisi e Ricci (2014), a análise de texto é fundamental para identificar o conteúdo semântico de documentos institucionais disponibilizados para o público.

Como o relatório 20-F é o principal canal de comunicação de informações entre as empresas estrangeiras listadas na Nyse e os stakeholders, assume-se que tenha sido escrito de forma a representar a mensagem que a empresa deseja realmente transmitir para o mercado, divulgando nele, de certa forma, os valores, crenças e políticas organizacionais. Tais manifestações em texto traduziriam a cultura internamente presente. Os relatórios 20-F se destacam ainda por conter informações complementares àquelas exigidas nos princípios contábeis geralmente aceitos (Biddle, Seow \& Siegel, 1995), auxiliando os investidores na obtenção de informações mais amplas para a tomada de decisões.

Para caracterizar as tipologias culturais, foi utilizada a técnica sugerida por Fiordelisi e Ricci (2014), em que são agrupados sinônimos para cada tipologia, a partir da identificação do radical das palavras relacionado com a abordagem de cada tipologia. O conjunto de radicais para a tipologia cultural é denominado bag of words, compreendendo 140 radicais, assim distribuídos: 34 para a cultura colaborativa, 30 para a cultura criativa, 41 para a cultura competitiva e 35 para a cultura de controle (Fiordelisi \& Ricci, 2014). 
Tabela 1. Distribuição da amostra por tipologia de cultura, continente de origem e por sistema legal/jurídico

\begin{tabular}{|c|c|c|c|c|c|c|c|c|}
\hline \multicolumn{9}{|c|}{ PAINEL A - Distribuição por Setor } \\
\hline Setor/Ramo de atividade econômica & Empresas & Observações & $(\%)$ & $\begin{array}{l}\text { Desempenho } \\
\text { financeiro }\end{array}$ & $\begin{array}{l}\text { Cultura } \\
\text { colaborativa }\end{array}$ & $\begin{array}{l}\text { Cultura } \\
\text { criativa }\end{array}$ & $\begin{array}{l}\text { Cultura } \\
\text { competitiva }\end{array}$ & $\begin{array}{l}\text { Cultura de } \\
\text { controle }\end{array}$ \\
\hline Alimentos e bebidas & 17 & 102 & 12,06 & 2,24 & 25,52 & 15,05 & 40,98 & 18,45 \\
\hline Construção e mineração & 9 & 54 & 6,38 & 4,86 & 26,50 & 14,90 & 37,55 & 21,05 \\
\hline Equipamentos e serviços industriais & 29 & 174 & 20,57 & 3,03 & 27,00 & 13,63 & 40,23 & 19,15 \\
\hline Medicamentos e biotecnologia & 5 & 30 & 3,55 & 9,00 & 24,10 & 14,20 & 43,40 & 18,30 \\
\hline Mídia e telecomunicações & 21 & 126 & 14,89 & 7,15 & 25,23 & 13,73 & 43,30 & 17,73 \\
\hline Produtos de óleo e gás & 18 & 108 & 12,77 & 2,73 & 25,85 & 15,00 & 39,20 & 19,95 \\
\hline Produtos e serviços de saúde & 4 & 24 & 2,84 & 7,34 & 27,70 & 12,30 & 42,80 & 17,20 \\
\hline Químico & 3 & 18 & 2,13 & 4,21 & 27,00 & 13,40 & 39,50 & 20,10 \\
\hline Tecnologia da informação & 11 & 66 & 7,80 & 7,17 & 24,85 & 14,00 & 44,00 & 17,15 \\
\hline Utilidade pública & 13 & 78 & 9,22 & 2,49 & 25,27 & 14,73 & 41,13 & 18,87 \\
\hline Viagens e lazer & 7 & 42 & 4,96 & 4,05 & 27,70 & 12,80 & 40,50 & 19,00 \\
\hline Outros & 4 & 24 & 2,84 & 0,10 & 26,63 & 14,37 & 39,13 & 19,87 \\
\hline \multicolumn{9}{|c|}{ PAINEL B - Distribuição por Continente de Origem } \\
\hline Continente de origem & Empresas & Observações & $(\%)$ & $\begin{array}{l}\text { Desempenho } \\
\text { financeiro }\end{array}$ & $\begin{array}{l}\text { Cultura } \\
\text { colaborativa }\end{array}$ & $\begin{array}{l}\text { Cultura } \\
\text { criativa }\end{array}$ & $\begin{array}{l}\text { Cultura } \\
\text { competitiva }\end{array}$ & $\begin{array}{l}\text { Cultura de } \\
\text { controle }\end{array}$ \\
\hline África & 2 & 12 & 1,42 & 0,96 & 25,28 & 16,54 & 34,80 & 23,38 \\
\hline América Latina & 38 & 228 & 26,95 & 4,89 & 25,12 & 14,42 & 40,62 & 19,84 \\
\hline América Central e Caribe & 6 & 36 & 4,26 & 2,80 & 24,81 & 14,14 & 40,94 & 20,11 \\
\hline Ásia & 42 & 252 & 29,79 & 4,05 & 26,00 & 13,71 & 42,01 & 18,28 \\
\hline Europa & 53 & 318 & 37,59 & 4,41 & 25,47 & 14,41 & 40,91 & 19,20 \\
\hline \multicolumn{9}{|c|}{ PAINEL C - Distribuição por Sistema Legal/Jurídico } \\
\hline Sistema legal/Jurídico & Empresas & Observações & $(\%)$ & $\begin{array}{l}\text { Desempenho } \\
\text { financeiro }\end{array}$ & $\begin{array}{l}\text { Cultura } \\
\text { colaborativa }\end{array}$ & $\begin{array}{l}\text { Cultura } \\
\text { criativa }\end{array}$ & $\begin{array}{l}\text { Cultura } \\
\text { competitiva }\end{array}$ & $\begin{array}{l}\text { Cultura de } \\
\text { controle }\end{array}$ \\
\hline Common Law & 17 & 102 & 12,06 & 5,53 & 26,05 & 13,77 & 40,79 & 19,39 \\
\hline Civil Law & 80 & 480 & 56,74 & 4,28 & 25,13 & 14,53 & 40,80 & 19,54 \\
\hline Mixed Law & 44 & 264 & 31,20 & 3,91 & 25,96 & 13,84 & 41,68 & 18,52 \\
\hline Total & 141 & 846 & 100,00 & 4,10 & 25,65 & 14,38 & 41,10 & 18,87 \\
\hline
\end{tabular}

Fonte: Dados da pesquisa.

Nota: A Tabela 1 apresenta valores médios do desempenho financeiro e das tipologias culturais a partir do setor, do continente e do sistema legal. 
Cada conjunto de radicais tem o intuito de representar aspectos relativos às tipologias culturais corporativas (Fiordelisi \& Ricci, 2014). Assim, por exemplo, na cultura colaborativa alguns radicais expressam o trabalho em equipe (collab, cooperat, help, team) e as relações interpessoais (partner, people, human). Na cultura de controle, os radicais incluem fatores de hierarquia e descentralização ( hir, decentr), bem como de controle e de coordenação (control, coordin, mentor, monit). As culturas competitiva e criativa representam radicais que sinalizam estratégia (aggress, attack, compet, driv), risco e inovação (creat, experim, new, risk), respectivamente.

\begin{tabular}{|c|c|c|c|}
\hline Variável & Proxy & Operacionalização & Fonte de dados \\
\hline Tamanho & Ativo & Logaritmo natural do ativo total & \multirow{3}{*}{ Relatório 20-F } \\
\hline Endividamento & Dívida total & $\begin{array}{l}\text { Quociente entre a dívida total e } \\
\text { o ativo total da firma }\end{array}$ & \\
\hline $\begin{array}{l}\text { Efeito da crise financeira } \\
\text { na organização }\end{array}$ & Rentabilidade & $\begin{array}{l}\text { Dummy para as empresas que } \\
\text { apresentam ROA decrescente } \\
\text { em três anos seguidos }\end{array}$ & \\
\hline Crise Financeira do País & Produto Interno Bruto & $\begin{array}{l}\text { Taxa de crescimento }\left(\mathrm{PIB}_{\mathrm{i}, \mathrm{t}}-\right. \\
\left.\mathrm{PIB}_{\mathrm{i}, \mathrm{t}-1}\right) / \mathrm{PIB}_{\mathrm{i}, \mathrm{t}-1}\end{array}$ & World Bank Group \\
\hline Localização Regional & Ocidente e Oriente & $\begin{array}{l}\text { Dummy para empresas situadas } \\
\text { em países localizados no } \\
\text { ocidente e no oriente }\end{array}$ & - \\
\hline Sistema Legal & Common, Civil e Mixed Law & $\begin{array}{l}\text { Dummy para empresas situadas } \\
\text { em países com sistema common } \\
\text { law, civil law ou mixed law }\end{array}$ & Juriglobe (2015) \\
\hline $\begin{array}{l}\text { Desenvolvimento } \\
\text { Econômico }\end{array}$ & $\begin{array}{l}\text { Economia avançada e } \\
\text { emergente }\end{array}$ & $\begin{array}{l}\text { Dummy para empresas situadas } \\
\text { em países de economias } \\
\text { avançadas ou países de } \\
\text { economias emergentes }\end{array}$ & $\begin{array}{l}\text { International Monetary } \\
\text { Fund - IMF (2014) }\end{array}$ \\
\hline
\end{tabular}

Quadro 2. Variáveis de controle do estudo

Fonte: Elaborado pelos autores.

Para cada empresa, foram calculadas as quatro tipologias de cultura organizacional mediante o número de ocorrências dos radicais em cada relatório 20-F. A tipologia cultural representa a razão entre o total de radicais encontrado para cada tipologia e o total de radicais encontrado no relatório analisado. Dessa forma, supondo que seja identificado, em um único documento, 500 radicais de palavras para todas as tipologias e que destes foi identificado 120 para a tipologia colaborativa, tem-se que a cultura colaborativa da empresa é de $24 \%(120 / 500)$. O procedimento é repetido para as demais tipologias, ou seja, cada empresa tem seus dados analisados para as quatro tipologias culturais adotadas no estudo.

Para avaliação do desempenho, foi utilizado o retorno sobre o ativo (Return on Assets - ROA), medido pela relação entre o lucro líquido e o ativo total (médio do período), utilizado por Ahmed e Shafiq (2014), Fekete e Böcskei (2011), Han (2012), Tseng (2010) e Yesil e Kaya (2013).

O Quadro 2 apresenta as variáveis de controle utilizadas na análise de regressão. A localização regional emergiu a partir da sugestão de Deshpandé e Farley (2004), ao encontrarem evidências empíricas de que a cultura organizacional varia entre países ricos e pobres, entre oriente e ocidente e entre economias emergentes e desenvolvidas. Deve-se observar que sistema legal/jurídico pode ser representado de três formas e a classificação dos países foi obtida no website do Juriglobe. Common law é a estrutura jurídica baseada em leis, enquanto que civil law baseia-se na jurisprudência e nos costumes. Mixed law representa países em que há a combinação de elementos dos sistemas common e civil law. O produto interno bruto (PIB) dos países foi obtido no website do Banco Mundial . Além destas, foram incluídas variáveis dummy de setor e ano, a fim de controlar a relação entre a cultura e o desempenho corporativo. O setor foi coletado junto à Securities and Exchange Commission .

A Tabela 2, Painel A, apresenta a média e o teste t para comparação do desempenho e das tipologias culturais a partir das variáveis de controle, enquanto que, no Painel B, apresenta-se a matriz de correlação. 
Tabela 2. Desempenho e tipologias culturais a partir das variáveis de controle

\begin{tabular}{|c|c|c|c|c|c|c|c|c|c|}
\hline \multicolumn{10}{|c|}{ PAINEL A - Comparação de médias } \\
\hline Característica & & Obs. & $(\%)$ & Desempenho & Colaborativa & Criativa & Competitiva & Controle & \\
\hline \multirow[t]{2}{*}{ Localização Regional } & Oriente & 282 & 33,3 & $0,863 * *$ & $0,259 * *$ & $0,138 * * *$ & $0,418 * * *$ & $0,184 * * *$ & \\
\hline & Ocidente & 564 & 66,7 & 0,129 & 0,252 & 0,144 & 0,406 & 0,196 & \\
\hline \multirow[t]{3}{*}{ Sistema Legal } & Common Law & 102 & 12,1 & $0,210 * * *$ & $0,261 * * *$ & $0,138 * * *$ & $0,407 * * *$ & $0,194 * * *$ & \\
\hline & Civil Law & 480 & 56,7 & 0,115 & 0,251 & 0,145 & 0,408 & 0,195 & \\
\hline & Mixed Law & 264 & 31,2 & 0,077 & 0,260 & 0,138 & 0,417 & 0,185 & \\
\hline \multirow[t]{2}{*}{ Desenvolvimento Econômico } & Emergente & 438 & 51,8 & $0,086^{* * *}$ & 0,255 & 0,141 & 0,409 & $0,193^{*}$ & \\
\hline & Avançada & 408 & 48,2 & 0,145 & 0,254 & 0,143 & 0,412 & 0,191 & \\
\hline \multirow[t]{2}{*}{ Efeitos da Crise Financeira } & Não & 597 & 48,2 & $0,146 * * *$ & $0,256^{*}$ & 0,143 & 0,410 & $0,191^{*}$ & \\
\hline & Sim & 249 & 29,4 & 0,041 & 0,252 & 0,141 & 0,413 & 0,194 & \\
\hline \multicolumn{10}{|c|}{ PAINEL B - Matriz de correlação (Variáveis contínuas) } \\
\hline Variável & Média & Desempenho & Colaborativa & Criativa & Competitiva & Controle & Tamanho & Endividamento & $\begin{array}{l}\text { Crise } \\
\text { Financeira do } \\
\text { País }\end{array}$ \\
\hline Desempenho & 0,115 & 1,00 & & & & & & & \\
\hline Colaborativa & 0,255 & $0,08^{* *}$ & 1,00 & & & & & & \\
\hline Criativa & 0,142 & $-0,07 *$ & $-0,39 * * *$ & 1,00 & & & & & \\
\hline Competitiva & 0,411 & 0,02 & $-0,45 * * *$ & $-0,40 * * *$ & 1,00 & & & & \\
\hline Controle & 0,192 & $-0,08^{* *}$ & $-0,27 * * *$ & $0,18^{* * *}$ & $-0,53 * * *$ & 1,00 & & & \\
\hline Tamanho & 9184 & 0,01 & 0,00 & $0,17 * * *$ & $-0,11 * * *$ & 0,01 & 1,00 & & \\
\hline Endividamento & 0,552 & $0,14^{* * *}$ & $-0,10^{* * *}$ & $0,07 * *$ & 0,01 & 0,04 & $0,18^{* * *}$ & 1,00 & \\
\hline Crise Financeira do País & 0,052 & $-0,08^{* *}$ & $0,12 * * *$ & $-0,14 * * *$ & $-0,01$ & 0,00 & 0,00 & $-0,11 * * *$ & 1.00 \\
\hline
\end{tabular}

Fonte: Dados dapesquisa.

Fonte: Dados da pesquisa.
Nota: ${ }^{* * *} \mathrm{e}^{* * *}$ representam níveis de significância ao nível de $10 \%, 5 \%$ e $1 \%$, respectivamente. 
Parte representativa das empresas está localizada no ocidente $(66,7 \%)$ e em países que adotam o sistema legal civil law (56,7\%). Embora as empresas tenham ações negociadas em um mercado de capitais bastante desenvolvido, a maioria delas está sediada em países de economia emergente $(51,8 \%)$.

As empresas estrangeiras listadas na Nyse apresentam, em média, 11,5\% de rentabilidade. As empresas têm tipologia cultural competitiva, com uma média de 41,1\%, seguida pelas tipologias colaborativa, de controle e criativa. Fiordelisi e Ricci (2014) encontraram evidências semelhantes nas empresas sediadas nos EUA. A proporção dessas tipologias sugere que mesmo empresas não sediadas nos EUA, mas negociando seus ativos na Nyse, apresentam predomínio de características competitivas, seja por carregar essa característica do próprio mercado em que atua, seja por adquirir essa característica junto ao mercado norte-americano (Selnes, Jaworski \& Kohli, 1996).

Empresas latino-americanas e europeias apresentam maiores níveis de cultura competitiva, com média de 40,9\%, enquanto que empresas asiáticas apresentam maior nível em cultura colaborativa, com média de $26,0 \%$ (Tabela 1). Empresas localizadas no ocidente apresentam maiores percentuais de cultura criativa e de controle, pertencentes a países como, por exemplo, Argentina, Brasil, Inglaterra, França e Espanha.

Aplicou-se análise de regressão, estimado pelo método dos mínimos quadrados ordinários, com utilização de dados em painel, adotando-se modelos econométricos para lidar com a associação entre as tipologias culturais e o desempenho. $\mathrm{Na}$ equação 1, foram utilizadas as variáveis independentes relativas às tipologias culturais.

$$
\text { Desempenho }_{i, t}=\beta_{0}+\beta_{1} \text { Cultura }_{i, t}+\sum_{i=2}^{9} \beta_{i} \text { Controle }_{i, t}+\sum_{i=10}^{21} \beta_{i} \text { Setor }_{i, t}+\sum_{i=22}^{27} \beta_{i} \text { Período }_{i, t}+\varepsilon_{i, t}
$$

Em que, Desempenho: desempenho da empresa, representado pelo ROA; Cultura: tipologias culturais da empresa; sendo as tipologias representadas, individualmente, pela participação da cultura colaborativa, criativa, competitiva e de controle; Controle: variáveis de controle, representadas pelo: tamanho, endividamento, efeito da crise financeira, crise financeira do país, localização regional, sistema legal (common law e civil law), desenvolvimento econômico e setor; $i$ e $t$ são os subscritos que representam a empresa e o tempo, respectivamente; $\beta$ : intercepto e; $\varepsilon$ : termo de erro estocástico da regressão em painel.

Foram aplicados testes de Breusch-Pagan, Shapiro-Wilk e Variance Inflation Factor (VIF) para verificar heterocedasticidade, normalidade e multicolinearidade. Para identificar a abordagem em painel foram realizados os testes de LM (Lagrange multiplier) de Breusch-Pagan e o teste de Hausman. Os testes foram realizados no Data Analysis and Statistical Software (Stata).

Para análise de sensibilidade dos resultados, foi realizada a análise do efeito das tipologias culturais no desempenho das empresas a partir dos fatores institucionais continente e sistema legal/jurídico, a fim de controlar de forma ampla outras características regionais. Em função de uma limitação amostral, não é possível analisar a relação entre o desempenho e a tipologia cultural nas demais variáveis do estudo.

\section{ANÁLISE E DISCUSSÃO DOS RESULTADOS}

\subsection{Tipologias culturais e desempenho corporativo}

Com base na Tabela 3, observa-se que todos os modelos se mostraram significantes, com um poder de explicação médio de $22,2 \%$. Os resultados indicam que apenas as tipologias culturais colaborativa e de controle afetam o desempenho das empresas.

Estudos anteriores mostram que a cultura colaborativa está relacionada positivamente com o desempenho (Fekete \& Böcskei, 2011; Han, 2012; Acar \& Acar, 2014), corroborando os achados da pesquisa. Esse resultado parece indicar que as empresas da amostra valorizam a participação dos empregados e incentivam o trabalho em equipe (Quinn \& Spreitzer, 1999). Dessa forma, percebe-se que a cultura colaborativa, por meio desses atributos, é capaz de afetar o desempenho, confirmando-se $\mathrm{H}_{1 \mathrm{a}}$. 
Tabela 3. Influência das tipologias culturais no desempenho das empresas

\begin{tabular}{|c|c|c|c|c|c|}
\hline Variáveis & (1a) & (1b) & (1c) & (1d) & (1e) \\
\hline \multirow[t]{2}{*}{ Cultura Colaborativa } & $1,201 * *$ & $0,975 * *$ & & & \\
\hline & $(0,014)$ & $(0,021)$ & & & \\
\hline \multirow[t]{2}{*}{ Cultura Criativa } & 0,283 & & $-0,457$ & & \\
\hline & $(0,615)$ & & $(0,258)$ & & \\
\hline \multirow[t]{2}{*}{ Cultura Competitiva } & 0,254 & & & $-0,389$ & \\
\hline & $(0,602)$ & & & $(0,303)$ & \\
\hline \multirow[t]{2}{*}{ Cultura de Controle } & Omitida (a) & & & & $-0,737 * *$ \\
\hline & & & & & $(0,033)$ \\
\hline \multirow[t]{2}{*}{ Tamanho } & $-0,019 *$ & $-0,019 *$ & $-0,019^{*}$ & $-0,019 *$ & $-0,017 * *$ \\
\hline & $(0,069)$ & $(0,076)$ & $(0,085)$ & $(0,083)$ & $(0,019)$ \\
\hline \multirow[t]{2}{*}{ Endividamento } & 0,170 & 0,170 & 0,165 & 0,160 & $-0,017 * *$ \\
\hline & $(0,211)$ & $(0,214)$ & $(0,226)$ & $(0,243)$ & $(0,018)$ \\
\hline \multirow[t]{2}{*}{ Efeito da Crise Financeira } & $-0,105^{* * *}$ & $-0,105^{* * *}$ & $-0,107 * * *$ & $-0,106^{* * *}$ & $-0,102 * * *$ \\
\hline & $(0,000)$ & $(0,000)$ & $(0,000)$ & $(0,000)$ & $(0,000)$ \\
\hline \multirow[t]{2}{*}{ Crise Financeira País } & $-0,226^{* *}$ & $-0,231 * *$ & $-0,209 * *$ & $-0,205 * *$ & $-0,157$ \\
\hline & $(0,032)$ & $(0,026)$ & $(0,039)$ & $(0,044)$ & $(0,143)$ \\
\hline \multirow[t]{2}{*}{ Localização Regional } & $-0,039$ & $-0,045$ & $-0,047$ & $-0,607$ & $-0,030$ \\
\hline & $(0,484)$ & $(0,428)$ & $(0,298)$ & $(0,306)$ & $(0,780)$ \\
\hline \multirow[t]{2}{*}{ Common Law } & 0,128 & 0,130 & 0,135 & 0,148 & 0,122 \\
\hline & $(0,192)$ & $(0,189)$ & $(0,161)$ & $(0,139)$ & $(0,280)$ \\
\hline \multirow[t]{2}{*}{ Civil Law } & 0,072 & 0,075 & 0,073 & 0,082 & 0,061 \\
\hline & $(0,306)$ & $(0,296)$ & $(0,298)$ & $(0,272)$ & $(0,562)$ \\
\hline \multirow[t]{2}{*}{ Desenvolvimento Econômico } & $0,045^{*}$ & $0,047^{*}$ & $0,047^{*}$ & $0,047^{*}$ & $0,043 * *$ \\
\hline & $(0,080)$ & $(0,071)$ & $(0,076)$ & $(0,083)$ & $(0,028)$ \\
\hline \multirow[t]{2}{*}{ Intercepto } & $-0,531$ & $-0,332 * *$ & 0,010 & 0,097 & 0,024 \\
\hline & $(0,122)$ & $(0,021)$ & $(0,925)$ & $(0,602)$ & $(0,801)$ \\
\hline Período & Sim & Sim & Sim & Sim & Sim \\
\hline Setor & Sim & Sim & Sim & Sim & Sim \\
\hline $\mathrm{N}(\mathrm{Obs})$ & $141(843)$ & $141(843)$ & $141(843)$ & $141(843)$ & $141(843)$ \\
\hline Wald-Chi2 & $118,36^{* * *}$ & $112.58 * * *$ & $108,02 * * *$ & $92,98 * * *$ & $101,10 * * *$ \\
\hline R2 Overall & $15,39 \%$ & $15,33 \%$ & $14,75 \%$ & $14,17 \%$ & $14,65 \%$ \\
\hline Teste Breusch-Pagan & $178,54 * * *$ & $183,70 * * *$ & $170,78 * * *$ & $172,45 * * *$ & $164,29 * * *$ \\
\hline Teste Shapiro-Wilk & $11,31 * * *$ & $11,30 * * *$ & $11,27 * * *$ & $11,30 * * *$ & 11,34 \\
\hline VIF médio & 5,44 & 5,50 & 5,48 & 5,51 & 5,49 \\
\hline
\end{tabular}

Fonte: Fonte: Dados da pesquisa.

Nota: Todos os modelos foram estimados sob efeitos aleatórios. Coeficientes estimados e erros padrão robustos a heterocedasticidade (entre parênteses). *,** e ***: significância ao nível de $10 \%, 5 \%$ e $1 \%$, respectivamente. (a) Variável omitida pela natureza da sua mensuração, por multicolinearidade.

As culturas corporativas competitivas e criativas não exercem efeito sobre o desempenho das empresas, refutando-se, assim, as hipóteses $\mathrm{H}_{1 \mathrm{~b}}$ e $\mathrm{H}_{1 \mathrm{c}}$. Para a cultura competitiva, os resultados refutam as evidências da literatura (Acar \& Acar, 2014; Fekete \& Böcskei, 2011; Han, 2012; Tseng, 2010), embora algumas pesquisas não tenham encontrado efeito da cultura competitiva sobre o desempenho (Han, 2012; Ogbonna \& Harris, 2000; Yesil \& Kaya, 2013), alinhando-se aos achados deste estudo. Para a cultura criativa, o estudo de Yesil e Kaya (2013) também corrobora os resultados aqui encontrados. 


\subsection{Análise de Sensibilidade}

De modo complementar, realiza-se a análise pelos mínimos quadrados generalizados, uma vez que se intenta corrigir erros de correlação com as variáveis independentes e a indiferença entre as variâncias dos erros existente nas variáveis de cultura, conforme apresentado na Tabela 4. Além disso, aplicou-se a regressão com variáveis instrumentais para minimizar problemas de endogeneidade dos regressores.

Tabela 4. Influência das tipologias culturais no desempenho

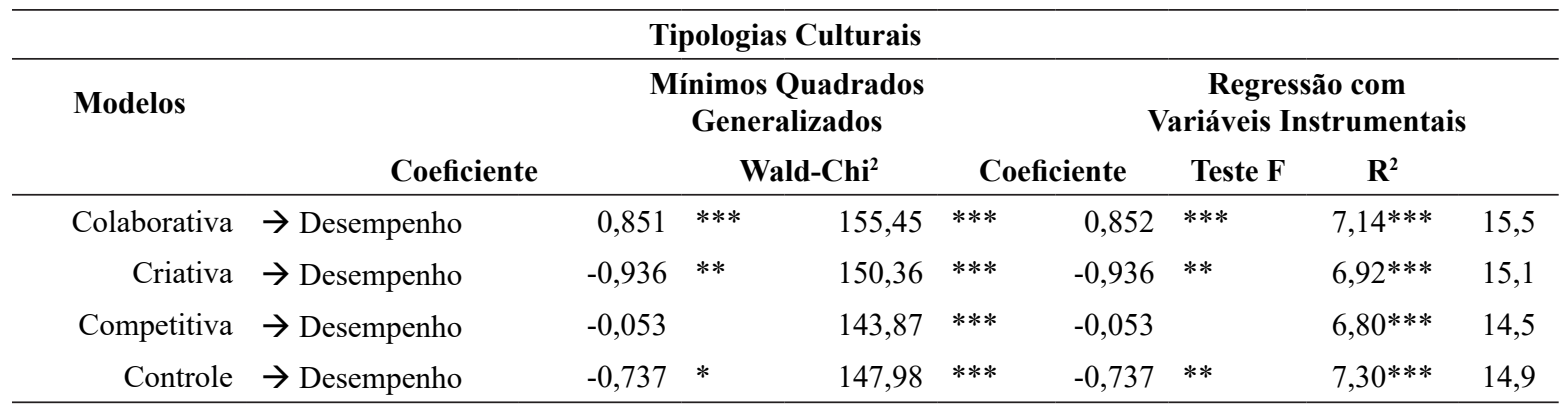

Fonte: Dados da pesquisa.

Nota: Coeficientes estimados e erros padrão robustos a heterocedasticidade. *, ** e ***: significância ao nível de $10 \%, 5 \%$ e $1 \%$, respectivamente.

Os resultados da Tabela 4 são próximos aos resultados estimados na Tabela 3, exceto para a tipologia criativa. As culturas colaborativa e de controle exercem influência positiva e negativa sobre o desempenho da empresa. Todavia, a cultura criativa mostra efeito negativo no desempenho. Posteriormente, verificou-se o efeito das tipologias da cultura no desempenho a partir dos continentes latino-americano, asiático e europeu (Tabela 5).

Tabela 5. Influência das tipologias da cultura no desempenho das empresas, por continente

\begin{tabular}{|c|c|c|c|c|c|c|c|}
\hline \multicolumn{8}{|c|}{ PAINEL A - América Latina (228 Observações) } \\
\hline \multicolumn{2}{|r|}{ Modelos } & \multicolumn{2}{|c|}{ Coeficiente } & \multicolumn{2}{|c|}{ Teste F } & \multirow{2}{*}{$\begin{array}{c}\mathbf{R}^{2}(\mathbf{\%}) \\
11,67\end{array}$} & \multirow{2}{*}{$\begin{array}{c}\begin{array}{c}\text { VIF } \\
\text { médio }\end{array} \\
2,66\end{array}$} \\
\hline Colaborativa & $\rightarrow$ Desempenho & \multicolumn{2}{|l|}{0,830} & 3,26 & $* * *$ & & \\
\hline Criativa & $\rightarrow$ Desempenho & \multicolumn{2}{|l|}{0,247} & 2,43 & $* * *$ & 10,66 & 2,70 \\
\hline Competitiva & $\rightarrow$ Desempenho & \multicolumn{2}{|l|}{$-0,600$} & 3,53 & $* * *$ & 11,53 & 2,64 \\
\hline Controle & $\rightarrow$ Desempenho & \multicolumn{2}{|l|}{$-0,031$} & 2,43 & $* * *$ & 10,59 & 2,65 \\
\hline \multicolumn{8}{|c|}{ PAINEL B - Ásia (252 Observações) } \\
\hline \multicolumn{2}{|r|}{ Modelos } & \multicolumn{2}{|c|}{ Coeficiente } & \multicolumn{2}{|c|}{ Teste $\mathbf{F}$} & $\mathbf{R}^{2}(\%)$ & $\begin{array}{c}\text { VIF } \\
\text { médio }\end{array}$ \\
\hline Colaborativa & $\rightarrow$ Desempenho & \multicolumn{2}{|l|}{0,491} & 3,93 & $* * *$ & 30,37 & 2,66 \\
\hline Criativa & $\rightarrow$ Desempenho & \multicolumn{2}{|l|}{$-0,931$} & 3,19 & $* * *$ & 30,60 & 2,64 \\
\hline Competitiva & $\rightarrow$ Desempenho & \multicolumn{2}{|l|}{0,475} & 4,20 & $* * *$ & 30,35 & 2,72 \\
\hline Controle & $\rightarrow$ Desempenho & \multicolumn{2}{|l|}{$-0,952$} & 3,51 & $* * *$ & 30,54 & 2,64 \\
\hline \multicolumn{8}{|c|}{ PAINEL C - Europa (318 Observações) } \\
\hline \multicolumn{2}{|r|}{ Modelos } & \multicolumn{2}{|c|}{ Coeficiente } & \multicolumn{2}{|c|}{ Teste $\mathbf{F}$} & $\mathbf{R}^{2}(\%)$ & $\begin{array}{c}\text { VIF } \\
\text { médio }\end{array}$ \\
\hline Colaborativa & $\rightarrow$ Desempenho & 1,167 & $* * *$ & 7,33 & $* * *$ & 20,94 & 2,07 \\
\hline Criativa & $\rightarrow$ Desempenho & $-1,628$ & $* *$ & 6,88 & $* * *$ & 2,56 & 2,18 \\
\hline Competitiva & $\rightarrow$ Desempenho & 0,037 & & 6,58 & $* * *$ & 19,56 & 2,39 \\
\hline Controle & $\rightarrow$ Desempenho & $-1,423$ & $* *$ & 7,70 & $* * *$ & 20,42 & 2,25 \\
\hline
\end{tabular}

Fonte: Dados da pesquisa.

Nota: Regressão com dados em painel na estrutura de pools. Coeficientes estimados e erros padrão robustos a heterocedasticidade. *, ** e *** representam nível de significância ao nível de $10 \%, 5 \%$ e $1 \%$, respectivamente. 
Os resultados da Tabela 5 mostram que, para empresas listadas na Nyse, somente no caso das empresas europeias a cultura organizacional parece afetar o desempenho da firma, com aumento do desempenho especificamente no caso da tipologia colaborativa, porém reduzindo o desempenho na presença de cultura criativa e de controle. Os testes mostram que o efeito da cultura difere a partir do continente. De todos os contextos analisados, as empresas oriundas do mercado europeu apresentam maior convergência com o que a abordagem da Visão Baseada em Recursos propõe.

Os achados corroboram os resultados de Ogbonna e Harris (2000), em que a tipologia de controle afeta negativamente o desempenho das empresas no Reino Unido. Além disso, os autores encontraram que a cultura competitiva afeta o desempenho das empresas. Acar e Acar (2014) também encontraram que empresas turcas têm seu desempenho positivamente afetado pela cultura competitiva. Em relação ao continente asiático, os estudos de Tseng (2010) e Han (2012) encontraram uma relação positiva entre a cultura colaborativa e o desempenho, divergindo do resultado deste estudo. Por último, realiza-se a análise das tipologias culturais e o desempenho a partir do sistema legal/jurídico do país sede das empresas (Tabela 6).

Tabela 6. Influência das tipologias culturais no desempenho das empresas, por sistema legal/jurídico

\begin{tabular}{|c|c|c|c|c|c|c|c|}
\hline \multicolumn{8}{|c|}{ PAINEL A - Common Law (102 Observações) } \\
\hline \multicolumn{2}{|c|}{ Modelos } & \multicolumn{2}{|c|}{ Coeficiente } & \multicolumn{2}{|c|}{ Teste $\mathbf{F}$} & \multirow{2}{*}{$\begin{array}{c}\begin{array}{c}\mathbf{R}^{2} \\
(\mathbf{\%})\end{array} \\
39,60\end{array}$} & \multirow{2}{*}{$\begin{array}{c}\begin{array}{c}\text { VIF } \\
\text { médio }\end{array} \\
3,31\end{array}$} \\
\hline Colaborativa & $\rightarrow$ Desempenho & 0,340 & & 6,07 & $* * *$ & & \\
\hline Criativa & $\rightarrow$ Desempenho & $-4,253$ & $* * *$ & 6,55 & $* * *$ & 42,90 & 3,39 \\
\hline Competitiva & $\rightarrow$ Desempenho & 0,019 & & 6,09 & $* * *$ & 39,50 & 3,46 \\
\hline Controle & $\rightarrow$ Desempenho & 1,826 & & 6,27 & $* * *$ & 40,40 & 2,07 \\
\hline \multicolumn{8}{|c|}{ PAINEL B - Civil Law (480 Observações) } \\
\hline \multicolumn{2}{|c|}{ Modelos } & \multicolumn{2}{|c|}{ Coeficiente } & \multicolumn{2}{|c|}{ Teste F } & $\begin{array}{l}\mathbf{R}^{2} \\
(\%)\end{array}$ & $\begin{array}{c}\text { VIF } \\
\text { médio }\end{array}$ \\
\hline Colaborativa & $\rightarrow$ Desempenho & 0,905 & $* *$ & 5,01 & $* * *$ & 11,87 & 3,19 \\
\hline Criativa & $\rightarrow$ Desempenho & 0,244 & & 4,63 & $* * *$ & 10,73 & 3,14 \\
\hline Competitiva & $\rightarrow$ Desempenho & $-0,434$ & & 4,71 & $* * *$ & 11,02 & 3,17 \\
\hline Controle & $\rightarrow$ Desempenho & $-0,922$ & $* * *$ & 4,94 & $* * *$ & 11,35 & 3,14 \\
\hline \multicolumn{8}{|c|}{ PAINEL C - Mixed Law (264 Observações) } \\
\hline \multicolumn{2}{|c|}{ Modelos } & \multicolumn{2}{|c|}{ Coeficiente } & \multicolumn{2}{|c|}{ Teste F } & $\begin{array}{c}\mathbf{R}^{2} \\
(\%)\end{array}$ & $\begin{array}{l}\text { VIF } \\
\text { médio }\end{array}$ \\
\hline Colaborativa & $\rightarrow$ Desempenho & 0,385 & & 4,03 & $* * *$ & 29,30 & 2,44 \\
\hline Criativa & $\rightarrow$ Desempenho & $-1,237$ & $* *$ & 3,28 & $* * *$ & 30,00 & 2,41 \\
\hline Competitiva & $\rightarrow$ Desempenho & 0,784 & $*$ & 3,97 & $* * *$ & 29,79 & 2,49 \\
\hline Controle & $\rightarrow$ Desempenho & $-1,056$ & & 3,64 & $* * *$ & 39,72 & 2,43 \\
\hline
\end{tabular}

Fonte: Dados da pesquisa.

Nota: Coeficientes estimados e erros padrão robustos a heterocedasticidade. $*$, ** e *** representam nível de significância ao nível de $10 \%, 5 \%$ e $1 \%$, respectivamente.

Em países cujo sistema legal é common law, somente a cultura criativa parece afetar o desempenho, e de forma negativa, ao contrário da expectativa de que o conhecimento gera inovação, que é, posteriormente, convertido em desempenho (Fekete \& Böcskei, 2011; Han, 2012; Ogbonna \& Harris, 2000).

Em países civil law, o desempenho da empresa é positivamente afetado pela cultura colaborativa e negativamente afetado pela cultura de controle. Países civil law possuem estrutura autoritária e codificada, bastante semelhante à estrutura de cultura de controle, em que os membros da organização acatam perfeitamente à autoridade que emana de papéis bem estabelecidos e de regas impostas pela empresa (Acar \& Acar, 2014). Esperase, portanto, que o desempenho da empresa seja influenciado por uma forte cultura de controle.

Em países cujo sistema é misto (mixed law), a cultura criativa afeta negativamente o desempenho, enquanto que a competitiva impacta positivamente. Quando os sistemas jurídicos dos países são unificados, as estruturas common e civil law expõem um comportamento completamente diferente. Essas evidências mostram que, de fato, o conjunto de fatores organizacionais e, principalmente, institucionais são capazes de causar distinções na cultura das empresas. 


\section{CONCLUSÕES}

Sob os preceitos da abordagem da Visão Baseada em Recursos, o estudo investigou a relação entre a cultura organizacional, atuante como recurso estratégico, e o desempenho das empresas estrangeiras listadas na Nyse. Foram analisados 846 relatórios modelo 20-F emitidos por 141 empresas listadas na Nyse entre 2009 e 2014. Observou-se que a tipologia de cultura organizacional competitiva é a mais predominante nos relatórios das empresas, seguida pela tipologia colaborativa, o que revela a importância que as empresas da amostra imputam à sua permanência no ambiente competitivo e à valorização do capital intelectual dos empregados.

Conforme destacado pela Visão Baseada em Recursos, a cultura organizacional - considerada um recurso estratégico sustentável - de fato, pode afetar o desempenho empresarial, quando consideradas as tipologias culturais colaborativa e de controle. Quando analisado nos diferentes continentes e a partir dos diferentes sistemas legais/jurídicos, a tipologia cultural apresenta comportamento distinto quanto ao seu efeito no desempenho da firma, sugerindo a especificidade de cada mercado e país, provavelmente em função da cultura nacional.

A cultura, desenvolvida pelas empresas, já considerada como um componente de vantagem competitiva sustentável pela literatura (Barney, 1986, Flamholtz \& Randle, 2012), ao ser desconsiderada nos estudos, automaticamente assume-se que a cultura organizacional é incapaz de transformar, construir e distinguir o ambiente empresarial; contrariando os resultados encontrados neste e em estudos anteriores sobre o efeito das tipologias culturais.

Parte se deve ao recente desenvolvimento dessa literatura, e por problemas de definição ou delineamento na mensuração da cultura organizacional e de seus impactos, gerando conclusões inconsistentes acerca da sua relação com o desempenho empresarial (Kim et al., 2004). Contudo, sugere-se o aprofundamento das pesquisas e maior exploração da relação cultura-desempenho corporativo (Yesil \& Kaya, 2013). Destaca-se que a proxy de cultura utilizada neste estudo é limitada pela própria abordagem empírico-positivista adotada, tornando necessária a expansão e conexão com estudos de tipologias de cultural organizacional na literatura interpretativista.

\section{REFERÊNCIAS}

Acar, A. Z., \& Acar, P. (2014). Organizational culture types and their effects on organizational performance in Turkish hospitals. Emerging Markets Journal, 3(3), 17-31. DOI: https://emaj.pitt.edu/ojs/index.php/emaj/ article/view/47

Ahmed, M., \& Shafiq, Q. S. (2014). The impact of organizational culture on organizational performance: a case study of telecom sector. Global Journal of Management and Business Research: An Administration and Management, 14(3), 21-30. Disponível em: https://journalofbusiness.org/index.php/GJMBR/article/ view/1254

The World Bank. Gross Domestic Product (current US\$). Acesso em 15 junho de 2018, de https://data.worldbank. org/indicator/NY.GDP.MKTP.CD?view=map.

Barney, J. (1986). Organizational culture: can it be a source of sustained competitive advantage? Academic Management Review, 11(3), 656-665. Disponível em: https://www.jstor.org/stable/258317

Biddle, G. C., Seow, G. S., \& Siegel, A. F. (1995). Relative versus incremental information content. Contemporary Accounting Research, 12(1), 1-23. DOI: https://doi.org/10.1111/j.1911-3846.1995.tb00478.x

Cameron, K. S., \& Quinn, R. E. (1999). Diagnosing and changing organizational culture: based on the competing values framework. San Francisco: Addison-Wesley.

Cameron, K. S., Quinn, R. E., Degraff, J., \& Thakor, A. V. (2006). Competing values leadership: creating value in organisations. Cheltenham: Edward Elgar.

Deal, T. E., \& Kennedy, A. A. (1982). Corporate cultures: the rites and rituals of corporate life. Massachusetts: Addison-Wesley.

Deshpandé, R., \& Farley, J. U. (2004). Organizational culture, market orientation, inovaticeness, and firm performance: an international research odyssey. International Journal of Research of Marketing, 21(1), 3-22. DOI: https://doi.org/10.1016/j.ijresmar.2003.04.002

Duke II, J., \& Edet, G. H. (2012). Organizational culture as a determinant of non-governmental organization performance: primer evidence from Nigeria. International Business and Management, 4(1), 66-75. DOI: http://dx.doi.org/10.3968/j.ibm.1923842820120401.1135 
Fekete, H., \& Böcskei, E. (2011). Cultural waves in company performance. Research Journal of Economics, Business and ICT, 3, 38-42. DOI: ttps://doi.org/10.1016/j.sbspro.2013.06.455

Fiordelisi, F., \& Ricci, O. (2014). Corporate culture and CEO turnover. Journal of Corporate Finance, $28,66-82$. DOI: https://doi.org/10.1016/j.jcorpfin.2013.11.009

Flamholtz, E. G., \& Randle, Y. (2012). Corporate culture, business models, competitive advantage, strategic assets and the bottom line: theoretical and measurement issues. Journal of Human Resource Costing \& Accounting, 16(2), 76-94. DOI: https://doi.org/10.1108/14013381211284227

Gregory, B. T., Harris, S. G., Armenakis, A. A.; \& Shook, C. L. (2009). Organizational culture and effectiveness: A study of values, attitudes, and organizational outcomes. Journal of Business Research, 62, 673-679. DOI: https://doi.org/10.1016/j.jbusres.2008.05.021

Han, H. S. (2012). The relationship among corporate culture, strategic orientation, and financial performance. Cornell Hospitality Quarterly, 52(3), 207-219. DOI: https://doi.org/10.1177\%2F1938965512443505

Hartnell, C. A., Ou, A. Y., \& Kinicki, A. (2011). Organizational culture and organizational effectiveness: a metaanalytic investigation of the competing values framework's theoretical suppositions. Journal of Applied Psychology, 96(4), 677-694. DOI: 10.1037/a0021987

Juriglobe. World Legal Systems. University of Ottawa. Acesso em 10 de maio, 2017, de http://www.juriglobe.ca/ eng/index.php.

Kim, S., Lee, J., \& Yu, K. (2004). Corporate culture and organizational performance. Journal of Managerial Psychology, 19(4), 340-359. DOI: https://doi.org/10.1108/02683940410537927

Kotrba, L. M., Gillespie, M. A., Schmidt, A. M., Smerek, R. E., Ritchie, S. A., Denison, D. R. (2012). Do consistent corporate cultures have better business performance? Exploring the interaction effects. Human Relations, O(0), 1-22. DOI: http://journals.sagepub.com/doi/abs/10.1177/0018726711426352

Lee, S. K. J., \& Yu, K. (2004). Corporate culture and organizational performance. Journal of Managerial Issues, 19(4), 340-359. DOI: https://doi.org/10.1108/02683940410537927

Levinson, S. (2003). Language and mind: let's get the issues straight! In: Gentner, D., Golsin-Meadow, S. (Eds.). Language in Mind. Cambridge: MIT Press, p. 25-45.

Naor, M., Jones, J. S., Bernardes, E. S., Goldstein, S. M., \& Schroeder, R. (2014). The culture-effectiveness link in a manufacturing context: a resource-based perspective. Journal of World Business, 49(3), 321-331. DOI: https://doi.org/10.1016/j.jwb.2013.06.003

North, D. C. (1991). Institutions. Journal of economic perspectives, 5(1), 97-112. DOI: 10.1257/jep.5.1.97

Ogbonna, E., \& Harris, L. (2000). C. Leadership style, organizational culture and performance: empirical evidence from UK companies. International Journal of Human Resource Management, 11(4), 766-788. DOI: https:// doi.org/10.1080/09585190050075114

O’Reilly III, C. A., Caldwell, D. F., Chatman, J. A., \& Doerr, B. (2014). The promise and problems of organizational culture: CEO personality, culture and firm performance. Group \& Organization Management, 39(6), 595625. DOI: https://doi.org/10.1177\%2F1059601114550713

Quinn, R. E., \& Spreitzer, G. M. (1999). The road to empowerment: Seven questions every leader should consider. Organizational Dynamics, 25(2), 37-49. DOI: https://doi.org/10.1016/S0090-2616(97)90004-8

Santos, N. M. B. F. (1998). Cultura e desempenho organizacional: um estudo empírico em empresas brasileiras do setor têxtil. Revista Administração Contemporânea, 2(1), 47-66. DOI: http://dx.doi.org/10.1590/S141565551998000100004

Santos, N. M., Bronzo, M., Oliveira, M. P. V., \& Resende, P. T. V. (2014). Cultura organizacional, estrutura organizacional e gestão de pessoas como bases para uma gestão orientada por processos e seus impactos no desempenho organizacional. Brazilian Business Review, 11(3), 105-129. Disponível em: http://www. bbronline.com.br/_novo/artigos.asp?sessao=ready\&cod_artigo=965

Schein, E. H. Coming to a new awareness of organizational culture. (1984). Sloan Management Review, 25(2), 3-16. Disponível em: http:/www.sietmanagement.fr/wp-content/uploads/2016/04/culture_schein-1.pdf

Securities and Exchange Commission (SEC). Filings \& Forms. Acesso em 12 julho de 2015. Disponível em: https://www.sec.gov/edgar.shtml. 
Selnes, F., Jaworski, B. J., \& Kohli, A. K. (1996). Market orientation in United States and Scandinavian companies. A cross-cultural study. Scandinavian Journal of Management, 12(2), 139-157. DOI: https://doi. org/10.1016/0956-5221(95)00053-4

Stone, P. J., Dunphy, D. C., Smith, M. S., \& Ogilvie, D. M. (1966). The General Inquirer: a computer approach to content analysis. MIT Studies in Comparative Politics. MIT Press, Cambridge, U.S.

Tseng, S. (2010). The correlation between organizational culture and knowledge conversion on corporate performance. Journal of Knowledge Management, 14(2), 269-284. DOI: https://doi.org/10.1108/13673271011032409

Yesil, S., \& Kaya, A. (2013). The effect of organizational culture on firm financial performance: evidence from a developing country. Procedia-Social and Behavioral Sciences, 81, 428-437. DOI: https://doi.org/10.1016/j. sbspro.2013.06.455

\section{Como citar este artigo}

Parente, P. H. N., De Luca, M. M. M., Lima, G. A. S. F. \& Vasconcelos, A. C. (2018). Cultura organizacional e desempenho nas empresas estrangeiras listadas na NYSE. Revista de Contabilidade e Organizações, 12:e139161. DOI: http://dx.doi.org/10.11606/issn.1982-6486.rco.2018.139161 
CULTURA ORGANIZACIONAL E DESEMPENHO NAS EMPRESAS ESTRANGEIRAS LISTADAS NA NYSE

MATERIAL SUPLEMENTAR

\begin{tabular}{ll}
\hline País & Empresa \\
\hline África do Sul & AngloGold Ashanti Limited \\
& Gold Fields Limited \\
\hline Alemanha & Fresenius Medical Care AG \& Co. KGaA \\
& SAP SE \\
\hline Argentina & Empresa Distribuidora y Comercializadora \\
& Norte S.A. (Edenor) \\
& Pampa Energia S.A. \\
& Petrobras Argentina S.A. \\
& Telecom Argentina S.A. \\
& YPF Sociedad Anónima \\
& Teekay Corporation \\
& Teekay LNG Partners L.P. \\
& Teekay Offshore Partners L.P. \\
& Teekay Tankers Ltd. \\
\hline Bahamas & Anheuser-Busch InBev NV \\
& Delhaize Group \\
\hline Bélgica & Textainer Group Holdings Limited \\
& Braskem S.A. \\
Bermudas & BRF - Brasil Foods S.A (formerly Perdigão \\
S.A.) \\
Companhia Brasileira de Distribuição \\
Companhia de Saneamento Básico do Estado de \\
São Paulo-Sabesp \\
Companhia Energetica de Minas Gerais-Cemig \\
Cosan Ltd. \\
CPFL Energia S.A. (CPFL) \\
Embraer S.A. \\
Fibria Celulose S.A. \\
Gafisa S.A. \\
Gerdau S.A. \\
GOL Linhas Aéreas Inteligentes S.A. (GOL) \\
Oi S.A. \\
Petróleo Brasileiro S.A.-PETROBRAS \\
Telefonica Brasil AS \\
TIM Participações S.A. \\
Ultrapar Participações S.A. \\
VALE S.A. \\
\hline
\end{tabular}




\begin{tabular}{|c|c|}
\hline \multirow[t]{5}{*}{ Chile } & Embotelladora Andina, S.A. \\
\hline & Empresa Nacional de Electricidad, S.A. (Chile) \\
\hline & Enersis, S.A. \\
\hline & LAN Airlines S.A. \\
\hline & Viña Concha y Toro, S.A. \\
\hline \multirow[t]{23}{*}{ China } & Acorn International, Inc. \\
\hline & $\begin{array}{l}\text { Aluminum Corporation of China Limited } \\
\text { (Chalco) }\end{array}$ \\
\hline & China Digital TV Holding Co., Ltd. \\
\hline & China Eastern Airlines Corporation Limited \\
\hline & China Mobile Limited (China Mobile) \\
\hline & China Nepstar Chain Drugstore Ltd. \\
\hline & $\begin{array}{l}\text { China Petroleum and Chemical Corporation } \\
\text { (Sinopec) }\end{array}$ \\
\hline & China Southern Airlines Company Limited \\
\hline & China Telecom Corporation Limited \\
\hline & China Unicom \\
\hline & CNOOC Limited \\
\hline & Concord Medical Services Holding Ltd. \\
\hline & Guangshen Railway Company Limited \\
\hline & Huaneng Power International, Inc. \\
\hline & Mindray Medical International Limited \\
\hline & PetroChina Company Limited \\
\hline & ReneSola Ltd \\
\hline & $\begin{array}{l}\text { Semiconductor Manufacturing International } \\
\text { Corporation (SMIC) }\end{array}$ \\
\hline & $\begin{array}{l}\text { Sinopec Shanghai Petrochemical Company } \\
\text { Limited }\end{array}$ \\
\hline & Trina Solar Limited (Trina) \\
\hline & WuXi PharmaTech (Cayman) Inc. \\
\hline & Yanzhou Coal Mining Company Limited \\
\hline & Yingli Green Energy Holding Company Limited \\
\hline Colômbia & Ecopetrol S.A. \\
\hline \multirow[t]{5}{*}{ Coreia } & Korea Electric Power Corporation \\
\hline & KT Corporation \\
\hline & LG Display Co., Ltd. \\
\hline & POSCO \\
\hline & SK Telecom Co., Ltd. \\
\hline Espanha & Telefónica S.A. \\
\hline Filipinas & Philippine Long Distance Telephone Company \\
\hline Finlândia & Nokia Corporation \\
\hline \multirow[t]{3}{*}{ França } & CGG \\
\hline & Sanofi S.A. \\
\hline & TOTAL S.A. \\
\hline
\end{tabular}




\begin{tabular}{|c|c|}
\hline Grécia & $\begin{array}{l}\text { Aegean Marine Petroleum Network } \\
\text { Danaos Corporation } \\
\text { Diana Shipping Inc. } \\
\text { Safe Bulkers, Inc. } \\
\text { Tsakos Energy Navigation Limited (TEN) }\end{array}$ \\
\hline Holanda & $\begin{array}{l}\text { AerCap Holdings N.V. } \\
\text { Koninklijke Philips Electronics N.V. } \\
\text { Reed Elsevier NV } \\
\text { Unilever N.V. }\end{array}$ \\
\hline Hong Kong, China & $\begin{array}{l}\text { MFC Industrial Ltd. } \\
\text { Nam Tai Electronics, Inc. (Namtai) }\end{array}$ \\
\hline Irlanda & $\begin{array}{l}\text { CRH plc (CRH) } \\
\text { Fly Leasing Ltd. }\end{array}$ \\
\hline Israel & $\begin{array}{l}\text { Blue Square-Israel Ltd. } \\
\text { Cellcom Israel, Ltd. } \\
\text { Ellomay Capital Ltd. } \\
\text { Teva Pharmaceutical Industries Limited }\end{array}$ \\
\hline Itália & $\begin{array}{l}\text { ENI S.p.A. } \\
\text { Luxottica Group, S.p.A. } \\
\text { Natuzzi, S.p.A. } \\
\text { Telecom Italia S.p.A. }\end{array}$ \\
\hline Japão & Canon Inc. \\
\hline Luxemburgo & $\begin{array}{l}\text { Arcelor Mittal } \\
\text { Tenaris S.A. } \\
\text { Ternium S.A. } \\
\end{array}$ \\
\hline México & $\begin{array}{l}\text { América Móvil, S.A.B. de C.V. } \\
\text { CEMEX S.A.B. de C.V. (CEMEX) } \\
\text { Coca-Cola FEMSA, S.A.B. de C.V. } \\
\text { Empresas ICA, S.A. de C.V. } \\
\text { Gruma S.A. de C.V. } \\
\text { Grupo Aeroportuario del Pacífico, S.A.B. de } \\
\text { C.V. (GAP) } \\
\text { Grupo Televisa, S.A. } \\
\text { Industrias Bachoco, S.A.B. de C.V. (Bachoco ) }\end{array}$ \\
\hline Mônaco & $\begin{array}{l}\text { Navios Maritime Holdings Inc. } \\
\text { Navios Maritime Partners L.P. } \\
\text { Scorpio Tankers Inc. }\end{array}$ \\
\hline Noruega & $\begin{array}{l}\text { DHT Holdings Inc. } \\
\text { Frontline Ltd. } \\
\text { Nordic American Tanker Shipping Ltd. } \\
\text { SeaDrill Ltd. } \\
\text { Ship Finance International Limited } \\
\text { Statoil ASA }\end{array}$ \\
\hline Panamá & Copa Holdings, S.A. \\
\hline Peru & Compañía de Minas Buenaventura S.A. \\
\hline
\end{tabular}




\begin{tabular}{ll}
\hline Reino Unido & BP p.l.c. \\
& GlaxoSmithKline plc \\
& Global Ship Lease, Inc. \\
& InterContinental Hotels Group plc \\
& Pearson Plc \\
& Reed Elsevier PLC \\
& Rio Tinto Plc \\
& Royal Dutch Shell plc \\
& Smith \& Nephew plc \\
& Unilever PLC \\
& Mechel OAO \\
& Mobile TeleSystems OJSC \\
\hline Rússia & China Yuchai International Limited \\
& ABB Ltd \\
\hline Singapura & Novartis AG \\
\hline Suíça & STMicroelectronics N.V. \\
& Syngenta AG \\
\hline Taiwan & Advanced Semiconductor Engineering, Inc. \\
& (ASE) \\
& AU Optronics Corp. \\
& Chunghwa Telecom Co., Ltd. (CHT) \\
& Taiwan Semiconductor Manufacturing \\
& Company Ltd. (TSMC) \\
& United Microelectronics Corporation (UMC) \\
\hline Turquia & Turkcell Iletisim Hizmetleri A.S. \\
\hline & \\
\hline
\end{tabular}

